\title{
Identidades e Políticas Coloniais: guaranis, índios infiéis, portugueses e espanhóis no Rio da Prata, c. $1750-1800$
}

Elisa Frühauf Garcia*

Resumo: Até recentemente, a historiografia sobre o Rio da Prata apresentava as relações de aliança vigentes na região de maneira um tanto esquemática: os guaranis missioneiros estariam sempre associados aos espanhóis e os minuanos, aos portugueses. Acompanhando as novas perspectivas sobre a história dos índios e enfocando tanto o espaço das missões quanto a região da campanha, paulatinamente tais relações vêm sendo percebidas em sua complexidade, que incluía também aproximações amistosas e eventuais alianças políticas dos grupos supostamente antagônicos. O artigo pretende abordar as interações entre os diversos agentes lá presentes, considerando os usos que eles faziam dos diferentes espaços e das diretrizes imperiais, enfatizando como as suas iniciativas e prioridades nem sempre se coadunavam às rígidas classificações coloniais da população indígena. Palavras-chave: Índios infiéis. Guaranis. Fronteiras. Missões.

O governo espanhol da América, como é bem conhecido pelo público especializado, ancorava-se na política de separação da população em duas repúblicas distintas: a dos índios e a dos espanhóis. De acordo com tal modelo, os índios inseridos diretamente no mundo colonial deveriam viver em um determinado território, mantidos afastados o máximo possível de quaisquer contatos com os demais

\footnotetext{
* Doutora em História - Professora da UFF. E-mail: elisafg@terra.com.br. Endereço: Rua Silveira Martins, 150/802 Rio de Janeiro - RJ
} 
segmentos da população. Afinal, como sintetizou Jacques PoloniSimard (2005, p. 3), "el buen gobierno de las Indias correspondía a una segregación”. Apesar dos limites de tal política, cuja aplicação variou consideravelmente no tempo e no espaço, para grande parte da historiografia sobre a América colonial, a experiência missioneira dos jesuítas no Paraguai teria sido um exemplo do sucesso do princí-

(0) pio de separação, ao conseguir manter os missioneiros afastados dos contatos com os ibéricos e com os índios não aldeados.

As regiões fronteiriças do Império espanhol, como era o caso do Rio da Prata, eram também ocupadas por uma população indígena chamada de não submetida, ou infiéis, frequentemente representada como um entrave ao pleno funcionamento e expansão da sociedade colonial. Além disso, tais regiões eram disputadas pelos estados europeus, envolvidos na ocupação do território americano, especialmente portugueses no caso platino. Assim, nesses espaços o estabelecimento das missões atendia ainda a fins eminentemente estratégicos: como já destacado reiteradamente pela historiografia, as missões foram organizadas em função da defesa do território contra as pretensões expansionistas dos estados concorrentes e dos ataques da população indígena não submetida (BOLTON, 1990; BOXER, 1989). Em semelhante contexto, a divisão entre duas categorias de índios, geralmente traduzida em termos dicotômicos, amigos e inimigos, correspondiam às próprias necessidades do governo colonial: não dispondo dos recursos necessários para fazer frente a tais ameaças, os índios aldeados deveriam funcionar como bastiões na defesa dos interesses dos respectivos monarcas.

No processo de disputa luso-castelhana pela ocupação da região do Rio da Prata, tal classificação da população nativa foi desdobrada pela historiografia, com uma simplicidade excessiva a meu ver, em aliados definitivos das frentes em disputa: os missioneiros, pela sua posição no império espanhol, estariam sempre associados aos castelhanos. Já os minuanos, por sua vez, atuariam incondicionalmente ao lado dos portugueses (GARCIA, 2009). Nesse tipo de abordagem, as relações entre os índios refletiriam as disputas europeias, cujos interesses seriam, em alguma medida, representados naquele espaço pela dicotomia missioneiros versus 
minuanos e, eventualmente, outros grupos classificados como infiéis, como charruas e guenoas. ${ }^{1}$

Ao reproduzir semelhante visão por décadas, a historiografia, implícita ou explicitamente, reificava o discurso colonial que dividia os espaços e as populações nativas de acordo com os interesses políticos e estratégicos ibéricos. Nesse sentido, ao tomar as classificações étnicas, diretamente formadas ou ressignificadas no processo de colonização, como dados objetivos, acabava encobrindo que tais categorias remontam muito mais a aspectos políticos e relacionais do que propriamente a determinados elementos constituintes de tais grupos, como demonstraram vários autores. ${ }^{2}$ Por outro lado, tais interpretações ainda desconsideravam os interesses dos diversos agentes presentes na classificação da população nativa, cujos objetivos muitas vezes estavam associados à manutenção de determinados estereótipos sobre os índios.

As representações de alguns grupos como essencialmente belicosos, por exemplo, serviam a vários agentes sociais de maneira distinta, por vezes aos próprios índios. Em certas situações, beneficiava funcionários da coroa que, ao apresentarem-se como uma garantia para a segurança da região, conseguiam se manter em seus postos. Os colonos, por sua vez, também utilizavam tais estereótipos a seu favor: poderiam atribuir aos índios atos de violência por eles praticados (ORTELLI, 2007). Semelhante representação poderia ainda ser produzida e difundida pela própria coroa, como uma estratégia para manter os colonos afastados de determinada área, como ocorreu no leste das Minas Gerais no período áureo da mineração (LANGFUR, 2002). Os índios, por sua vez, também valiam-se de tal expediente: a fama de belicosos ajudava a manter afastadas as frentes de expansão da sociedade colonial (LANGFUR, 2002). Além disso, em detrimento de uma rivalidade absoluta, grupos supostamente inimigos alternavam momentos de conflito com situações de convivência amistosa, revelando assim um processo complexo em que as identidades mais do remeterem a uma determinada essência, eram definidas no jogo dos interesses e das diferentes relações de força entre os agentes em contato.

Para o caso da província jesuítica do Paraguai, a própria associação entre os guaranis e as missões já traz desdobramentos 
significativos, ao desconsiderar a heterogeneidade da população inserida nas reduções e tomar a identidade guarani, em alguma medida, como anterior à sua inserção na sociedade colonial. Nesse sentido, é importante ressaltar que a historiografia tem apontado recentemente para a presença de uma população de origem infiel nos pueblos e para a historicidade dos guaranis, embora isso apareça mais como uma

( proposta do que propriamente nos resultados apresentados nas pesquisas (SANTOS; BAPTISTA, 2007). De maneira geral, ainda que implicitamente, os trabalhos continuam priorizando a existência de determinados elementos constituintes das identidades indígenas em detrimento de um enfoque histórico e relacional.

A presença de uma população heterogênea no interior das missões era certamente um dos elementos-chave para a manutenção de relações com os índios da campanha. A documentação sobre a região apresenta fartas informações sobre a presença de infiéis nos pueblos de missões, para onde dirigiam-se com bastante frequência, especialmente a fim de visitarem os seus parentes e de obterem determinadas mercadorias, especialmente erva-mate e tabaco. ${ }^{3} \mathrm{~A}$ situação era tal que mesmo os jesuítas, principais construtores de uma visão homogênea do espaço missioneiro, tinham dúvidas sobre as lealdades dos reduzidos (WILDE, 2009). Em 1707, por exemplo, ao preparar um ataque contra os guenoas, os missionários julgaram prudente enviar os seus parentes cristãos a um pueblo mais distante. A precaução aponta para a existência de uma série de critérios, além do religioso, na construção e manutenção das relações sociais. Assim, apesar de aldeados e cristianizados, os jesuítas consideravam que os guenoas poderiam servir de "[...] espias duplos, que avisassem aos seus parentes de todos nossos desígnios". ${ }^{4}$

Os portugueses, por sua vez, a despeito de utilizarem as alianças com os infiéis, também tinham dúvidas sobre o quanto poderiam confiar neles, como pode-se perceber em um caso ocorrido no final da década de 1740. Na ocasião, um grupo de minuanos, cujos contatos com os lusos eram frequentes, ficou sabendo dos seus projetos de atacar as missões do Paraguai. Apesar de acertarem a participação no ataque, os índios não titubearam em avisar aos seus parentes cristãos aldeados do perigo iminente. O relato do padre Nusdorfer é elucidativo quanto à natureza mutável e contextual das alianças e 
identidades étnicas vigentes na região. Para o inaciano, os minuanos eram "infiéis sem lei", portanto usualmente não daria crédito às suas informações. $\mathrm{O}$ caso em questão, porém, envolvia seus parentes e, baseado na experiência, afirmava que "[...] tienen algum amor a sus parientes christianos que ay en los Pueblos", e costumam "[...] decirles la verdad". 5

Os missioneiros, por sua vez, também frequentavam os grupos de infiéis, juntando-se a eles temporária ou definitivamente. Segundo os relatos, motivos para isso não faltavam: desejo de trocar de parceiros amorosos e sexuais, vontade de trabalhar para si e não para a comunidade, dentre outros. Os próprios missionários narravam com frequência as "fugas" dos missioneiros para junto dos infiéis, nas quais se dedicavam a "roubos", principalmente de gado. Os jesuítas ainda caracterizavam os grupos de infiéis como um reduto de apóstatas, onde tanto índios aldeados quanto espanhóis abandonavam a religião católica e praticavam toda a sorte de "feitiçarias" e "pactos com o demônio" (BRACCO, 2004). Para além da veracidade das informações ou da mera manifestação de uma retórica inaciana, cabe ressaltar que tais acusações revelam que vários membros da sociedade colonial consideravam juntar-se aos infiéis um recurso a ser empregado em diversas circunstâncias.

Além disso, apesar das acusações dos jesuítas muitas vezes se centrarem em aspectos religiosos, a opção pelos infiéis geralmente tinha motivos mais prosaicos, como pode-se perceber em um episódio narrado por José Cardiel em 1747. Na ocasião, quando encontrou um grupo de missioneiros que havia fugido para viver junto com os infiéis, os convidou para retornar aos pueblos. Os índios, porém, responderam que não lhes agradara o modo de vida lá experimentado, em que eram obrigados a trabalhar com castigos, e consideravam-se muito melhor agora, "[...] estando livres para mudar de amo e de terras quando lhes aprouvesse". ${ }^{6}$

Se as classificações coloniais não correspondiam automaticamente às práticas no cotidiano americano, elas tampouco podem ser consideradas apenas uma formalidade sem quaisquer efeitos na realidade social. Como destacou John Monteiro (2001, p. 57-58), mais do que meramente um instrumento de dominação da população nativa, as classificações coloniais foram também um elemento para 
a sua sobrevivência. No conjunto das estratégias elaboradas pelos índios, a habilidade para manejar tais classificações de acordo com as diferentes situações tinha um lugar de destaque. Essa possibilidade era potencializada nas regiões de fronteira, onde os estados europeus disputavam não apenas territórios, mas fundamentalmente a aliança com a população nativa. Esta, por sua vez, acabava por rapidamente dominar o cenário de disputa e tentava se inserir nos conflitos de acordo com as suas prioridades. ${ }^{7}$

Assim, não apenas os diferentes agentes associados ao estado colonial construíam suas próprias visões sobre os índios, marcadas tanto por suas respectivas percepções de mundo quanto motivadas por determinados interesses, mas também os índios valiam-se desse expediente, apresentando-se de maneira mais favorável, considerando os diferentes interlocutores e as conjunturas específicas. Como destacaram Jennifer Brown e Elizabeth Vibert (2003, p. 18), os textos produzidos pelos diversos agentes envolvidos em situações de contato revelam não apenas as suas representações sobre os índios. Trata-se, fundamentalmente, do resultado de diálogos, ainda que assimétricos, em que a população nativa desempenhava um papel ativo, omitindo, selecionando e informando aspectos que atenderiam aos seus objetivos.

Nesse sentido, a referência a conjunturas históricas específicas é fundamental para perceber as ações dos índios e as representações que construíam de si mesmos e dos demais agentes com os quais interagiam. No caso dos minuanos e demais grupos de infiéis, as suas aparentes oscilações entre a condição de aliados ou inimigos dos missioneiros inserem-se, sem dúvida, na imbricada rede de relações sociais da região, onde, quanto maior a disputa, maiores eram as vantagens oferecidas aos potenciais aliados nativos, como é facilmente perceptível na documentação. Em 1715, por exemplo, o rei de Portugal admoestava o novo governador da Colônia de Sacramento, Manoel Gomes Barbosa, a conservar:

[...] grande cautela com os índios vizinhos, mas com esta advertência que os não escandalizeis, antes procurareis atraílos com indústria, tendo entendido que a sua amizade vos pode servir de grande beneficio, e pelo contrário a sua inimizade de notável 
prejuízo; e que poderão os castelhanos com a mão destes bárbaros fazer-nos dano, e impedir-vos o uso da campanha, sem a qual não poderá subsistir a Colônia. ${ }^{8}$

Os minuanos, por sua vez, sabiam aproveitar as situações favoráveis nas disputas entre portugueses e espanhóis para alcançarem os seus objetivos. Possivelmente cientes da disposição que o novo governador deveria manter para com eles, três caciques o procuraram com a intenção de tornarem-se cristãos, porém sob uma condição: a de que fosse trazida do Rio de Janeiro uma sua irmã e sobrinha, a qual, não se sabe ao certo em quais condições, havia sido levada àquela cidade. A solicitação dos caciques obteve parecer favorável do Conselho Ultramarino, sob a justificativa de que só assim seriam obtidos benefícios com as pazes seladas com os minuanos, considerados então os mais valorosos da campanha. A sua irmã deveria ser localizada no Rio de Janeiro e, caso estivesse na condição de escrava, seria comprada à custa da fazenda real e, posteriormente, enviada ao Sul (ALMEIDA, 2003, p. 99).

Se a situação vigente já estava bastante influenciada pelas rivalidades luso-castelhanas, ela foi potencializada pela assinatura do Tratado de Madri que, caso fosse implementado mudaria consideravelmente a distribuição territorial e populacional na região. Durante os conflitos decorrentes das tentativas de sua demarcação, conhecidos genericamente como guerra guaranítica, a estratégia dos minuanos de utilização das categorias coloniais para obter determinados benefícios ficou evidente. Quando os missioneiros estavam se organizando para impedir a passagem das comissões demarcadoras, procuraram os minuanos em busca de aliança. Mediante presentes, eles acertaram a participação no conflito.

A situação, porém, não era tão simples assim: apesar de selarem a aliança, os missioneiros não confiavam plenamente nos minuanos e o tempo lhes deu razão, como se pode perceber no caso do cacique Moreira. Líder de um grupo minuano, Moreira apresentou-se aos missioneiros como aliado, solicitando alguns presentes, principalmente carne, tabaco e erva-mate. Segundo ele, utilizaria tais presentes para ir ao acampamento dos portugueses, onde possuía trânsito facilitado, e tentaria enganá-los. Os missioneiros aceitaram a proposta, 
mas na ocasião não conseguiram descobrir se a oferta era sincera ou se, ao contrário, os minuanos estavam mancomunados com os lusitanos (HENIS, 2002, p. 33-34, p. 40).

As desconfianças dos missioneiros não eram sem fundamento: o tal Moreira, quando os índios foram fazer frente ao exército português, entrou em conversação com Gomes Freire de Andrada, comissário chefe da demarcação da fronteira sul. Durante as negociações, Gomes Freire disse a Moreira que se sentia desconfortável com a união do seu grupo aos missioneiros, afinal ele sempre tinha sido amigo da "nação" minuana. Moreira, no entanto, contou outra versão sobre o seu acordo com os missioneiros. Segundo ele, os minuanos estavam com extrema necessidade de "coisas" e perceberam no acordo uma possibilidade de abastecer-se. Após esclarecer a situação com Gomes Freire, Moreira teria dito: “[...] que ele estava violento na companhia daquela gente [missioneiros]: se eu [Gomes Freire] lhe dava palavra de achar em mim o antigo amparo, ele moveria os seus a negar o socorro e se recolheriam a fortaleza de São Miguel".?

O importante a frisar nesse caso é como Moreira construiu a si e ao seu grupo no diálogo com Gomes Freire. As ações que teriam "desapontado" o general são imputadas a determinadas situações ou a terceiros, isentando-os de qualquer responsabilidade. Dessa forma, os minuanos não se aliaram aos missioneiros porque quiseram, mas sim pela necessidade na qual se encontravam. E, ainda mais importante, foi devido a essa aliança a qual se viram obrigados pelas circunstâncias, que estavam "violentos". As suas ações contrárias aos portugueses, portanto, não deveriam ser creditadas aos minuanos, mas sim às suas "más companhias": os missioneiros. A capacidade apresentada por Moreira de utilizar a situação a seu favor através do manejo das categorias dicotômicas é notável, mas é importante ressaltar que não vem ao caso se Gomes Freire acreditou ou não na versão. Hábil e experiente oficial português, sabia bem do que se tratava. Em outra ocasião, manifestou em que consistiam tais estratégias. Segundo Gomes Freire, "[...] os índios falam [...] o que é mais conveniente; danolo a ver a experiência". ${ }^{10}$ Porém, diante da necessidade de enfraquecer os missioneiros, Moreira sabia que Gomes Freire estaria disposto a aceitar a versão apresentada. A 
mensagem, portanto, fora calculada para ser bem recebida pelo receptor ao qual se destinava.

Devido às circunstâncias locais e à mudança das conjunturas imperiais, o Tratado de Madri foi anulado em 1761 e a situação permaneceu como antes. Nas décadas seguintes, os minuanos continuaram a relacionar-se com os missioneiros, ao que parece sem maiores ressentimentos pelas "traições" do passado, muitas vezes surpreendendo os próprios funcionários espanhóis. Segundo as fontes, os infiéis visitavam os pueblos com alguma regularidade. $\mathrm{Na}$ década de 1780, já após a expulsão dos jesuítas, Félix de Azara (1873, 174) assistiu a uma festa na redução de São Miguel e manifestou certa surpresa, não tanto com a presença dos charruas e minuanos, mas com a ausência de diferenças entre eles e os missioneiros. $\mathrm{Na}$ ocasião, durante a festa anual da redução, os charruas e minuanos usufruíram dos benefícios coletivos distribuídos na comemoração e ainda fizeram parte de uma representação dos conflitos já ocorridos na região. Nessa representação, os principais oponentes eram índios e espanhóis, e nenhuma menção foi feita aos portugueses ou a uma divisão entre missioneiros e infiéis.

$\mathrm{Na}$ época da festa presenciada por Azara, os minuanos estavam tentando um acordo vantajoso com os portugueses. Em maio de 1785, o cacique minuano Bartolomeu enviou, das próprias missões, uma carta ao governador interino do Continente de São Pedro, Rafael Pinto Bandeira, na qual solicitava licença para passar aos domínios de Portugal. Na carta, o cacique informava que:

[...] os castelhanos vieram falar conosco no Campo [... e] querem que nós cheguemos a Montevidéu, que nos darão tudo quanto nós quisermos e nós não queremos e antes queremos entregar-nos ao Rei de Portugal e também queremos passar o gado de São Nicolau e São Izidro para lá com toda a minha família e quero que Vossa Senhoria saiba disto e que nos conceda licença e espero de Vossa Senhoria a resposta. ${ }^{11}$

Pode-se ver como o cacique maneja muito bem as rivalidades entre os portugueses e os espanhóis a seu favor. Enfatiza que foi convidado para passar a Montevidéu, mas não quer. Ou melhor, 
prefere passar para os domínios dos portugueses, destacando que levará recursos para tanto e, assim, apresenta a proposta como um bom negócio para o Rei Fidelíssimo. As relações do grupo de dom Bartolomeu com os espanhóis, porém, não eram tão harmônicas quanto ele descreveu na carta. No breve período entre a correspondência e a deliberação das autoridades portuguesas sobre o assunto, o seu grupo foi "destroçado" pelos castelhanos, ficando dom Bartolomeu "sem gente" e vendo-se obrigado a juntar-se a outros caciques. ${ }^{12}$

O grupo de caciques minuanos ao qual se juntou dom Bartolomeu deu prosseguimento às negociações relativas à passagem aos domínios portugueses. Antes de tomar a decisão final, a administração lusitana solicitou que os caciques respondessem a algumas questões sobre as suas intenções. Estas eram:

- Que número de gente governa;

- Quantos homens, e quantas mulheres;

- Quais são os motivos que os obrigam a passar para os domínios de Portugal;

- Que número de animais pretendem trazer, declarando quanto de gado, quantos cavalos etc;

- Quais são as condições com que querem ser admitidos;

- Se precisam de auxílio para passarem, ou se poderão fazer sem ele;

- Que se deve conservar um impenetrável segredo, a fim de que os espanhóis não presumam de tal negócio;

- Em que tempo estão prontos a passar. ${ }^{13}$

O grupo que estava solicitando a passagem para as terras de Portugal era composto de cinco caciques, entre os quais dom Bartolomeu. Ao todo, eram em torno de mil pessoas, distribuídas em: "Minuanos de armas, digo de lanças 300 e tantos, mulheres 270 e tantas, menores 420 e tantos" e possuíam cerca de 4.396 animais. Respondendo às questões colocadas, os caciques alegavam que queriam ser vassalos de Dona Maria I, porque os portugueses tinham sido sempre seus amigos, mas, principalmente, porque os espanhóis estavam querendo expulsá-los dos “[...] campos, em que habitam, e 
seus antecessores de muitos séculos, que por direito são seus, por serem os primeiros povoadores deles", acrescentando ainda que o rei de Espanha queria matá-los. Os caciques também ofereciam-se para serem os primeiros a combater os espanhóis em qualquer guerra. ${ }^{14}$

Além de se queixarem aos portugueses dos espanhóis, algo que se tornou um hábito entre os minuanos, o mais relevante na negociação é a justificativa empregada pelo grupo. Eles se apresentam, primeiramente, como aliados históricos dos portugueses, explicando novamente a composição das forças em disputa na região em termos dicotômicos. Nesse sentido, manejam muito bem as rivalidades luso-castelhanas e omitem qualquer episódio passado que pudesse contradizer a sua versão, pois seriam os primeiros a combater os espanhóis e, mais do que isto, se posicionam ao lado dos lusitanos por terem um inimigo em comum.

Ao manejarem tais rivalidades, os minuanos não se colocavam em uma posição subalterna em relação aos portugueses: pelo contrário, apresentavam-se enquanto aliados úteis aos seus projetos expansionistas. No momento desta negociação, o início do último quartel do século XVIII, o território ocupado pelos minuanos estava sendo cada vez mais disputado pelas frentes colonizadoras ibéricas e, consequentemente, seu espaço se reduzindo. Como demonstrado por vários autores, tal período, se por um lado pode ser considerado em linhas gerais vantajoso para os índios, pois as políticas bourbônicas e pombalinas pressupunham uma série ofertas vantajosas por parte dos monarcas ibéricos, por outro também acarretava uma maior presença da sociedade colonial nos seus territórios, com a efetiva disposição das coroas em ocupar as suas fronteiras para a defesa dos respectivos impérios diante da crescente concorrência pela América. ${ }^{15}$

$\mathrm{Na}$ versão apresentada pelos caciques aos portugueses, porém, a situação era outra: não estavam ficando pressionados pelas duas frentes de expansão, mas apenas pelos espanhóis. Ou seja, neste momento específico, os minuanos, na sua interação com os lusitanos, recontam a sua história, reorganizando o seu presente e mostrando uma versão específica de um processo mais geral. Como demonstraram vários autores, os índios de diversas regiões da América reformulavam constantemente a sua percepção história a partir de 
questões colocadas pelo presente, quando utilizavam determinada visão do passado para repensar as suas condições atuais e planejar o futuro (RAPPAPORT, 1990; SIDER, 1994; HILL, 1992). Para o caso dos minuanos, suas falas e o contexto histórico parecem demonstrar que associavam à trajetória de aliança com os portugueses a possibilidade de terem um futuro, na medida em que buscavam uma saída para a situação periclitante na qual se encontravam.

Todo esse esforço, porém, dessa vez não foi suficiente para obter do vice-rei um parecer favorável. Segundo Luiz de Vasconcelos e Souza, tal aliança poderia suscitar desequilíbrios na relação dos portugueses com os espanhóis, justamente no momento em que tentavam estabelecer as divisas previstas no Tratado de Santo Ildefonso. Para o vice-rei, o número de vassalos e de animais não parecia suficiente para justificar o risco de uma possível inimizade espanhola, além de não acreditar na fidelidade dos índios, visto a sua natural "inconstância". ${ }^{16}$

A “inconstância" dos minuanos, frequentemente apontada por diversos agentes coloniais, nada mais era, em minha opinião, do que reflexos das suas diferentes escolhas e oportunidades em momentos específicos. Por outro lado, se os minuanos eram vistos como inconstantes pelos portugueses, provavelmente a recíproca era verdadeira. As políticas lusitanas também eram passíveis de modificações e elas nem sempre mantinham as mesmas disposições favoráveis para com os índios. Se no início do século XVIII e no contexto das tentativas de demarcação do Tratado de Madri os funcionários reais foram admoestados a preservarem a aliança com os minuanos, dispostos inclusive a aceitar, como fizera Gomes Freire no caso do cacique Moreira, as versões um tanto nebulosas sobre a sua conduta, o cenário, em meados de 1780, era outro. Agora, os minuanos até poderiam ser aliados úteis, mas não eram imprescindíveis e foram preteridos em favor da manutenção das boas relações com os castelhanos.

É importante destacar ainda como as diretrizes imperiais formuladas pela corte não eram cumpridas mecanicamente pelos funcionários locais, mas frequentemente submetidas a ponderações regionais e a avaliações pessoais. Como assinalou David Weber (2007) ao analisar as reformas bourbônicas em relação aos índios, as determinações da coroa eram apenas um dos aspectos a ser 
considerado e a possibilidade do monarca efetivamente controlar os agentes das regiões de fronteira era bastante limitada. A disposição para negociação poderia, como de fato foi em vários momentos, ser alternada com políticas mais agressivas dependendo principalmente dos funcionários reais, das reações dos índios e das reais possibilidades espanholas de dominar militarmente uma determinada região. Observação semelhante pode ser feita para o caso das medidas pombalinas: se elas eram favoráveis às negociações com os índios, sua efetiva aplicação obedecia a uma série de variáveis.

Os infiéis, porém, não desistiam tão fácil e alguns anos depois conseguiram o tão esperado acordo com os portugueses. Tal persistência, ao que parece, era recorrente em outras regiões da América onde os grupos subalternos dependiam das rivalidades europeias para a concretização dos seus projetos. Jane Landers (1990), em estudo sobre os escravos africanos que fugiam dos domínios ingleses na América do Norte para o nordeste da Flórida espanhola em busca de liberdade, demonstra como eles aprenderam a utilizar a seu favor as rivalidades anglo-espanholas. Porém, como assinalado pela autora, as diretrizes do governo espanhol em relação aos fugitivos variavam de acordo com considerações que envolviam desde o estado das relações diplomáticas com a Inglaterra até os diferentes pontos de vista dos governadores locais sobre a questão. No entanto, como para os escravos fugitivos o estabelecimento de alianças com o governo da Flórida era fundamental à sua sobrevivência, eles não desistiam quando encontravam uma conjuntura desfavorável.

Na virada do século XVIII para o XIX, disposição dos portugueses parecia novamente se inclinar a favor dos infiéis. Em 1800, o vice-rei do Rio da Prata, Marquês de Avilés, elaborou um plano para a fundação de novos povoados na campanha de Montevidéu, buscando assim guarnecer melhor a fronteira com o Brasil. Na visão dos castelhanos, os charruas e minuanos eram o principal óbice para o sucesso do projeto. Segundo Felix de Azara (1943, p. 17), para a obtenção do controle e estabelecimento de povoações na região de fronteira era fundamental: "[...] reducir á los infieles Minuanes y Charrues, ya sea pronta y ejecutivamente si hay bastante tropa, ó si esta es poca, adelantar nuestras estancias, cubriéndolas siempre". 
Avilés colocou então em prática um plano de aldeamento dos charruas e minuanos, mas não obteve muito sucesso. Após uma recepção inicial positiva, os índios mudaram de ideia e teriam dito que, além de não aceitarem as propostas do vice-rei, estavam em guerra com os cristãos: caso insistissem, seriam todos massacrados (BAUZA, 1929, p. 363-365). Frustradas as tentativas de aldeamento, a administração do Rio da Prata resolveu usar a força para expulsar os índios das terras onde pretendia fundar as novas povoações. Concomitantemente, os infiéis buscavam cada vez mais refúgio nos domínios do Rio Grande, causando a ira dos administradores coloniais de Montevidéu, pois praticavam roubos de gados nas estâncias, muitas vezes associados aos luso-brasileiros. Durante as fugas, entravam nas terras brasileiras, dificultando assim a perseguição das tropas espanholas, pois estas deveriam evitar atravessar a fronteira, sob pena de desencadear uma crise diplomática não desejada por nenhuma das cortes ibéricas naquele momento.

Com o acirramento da situação, os espanhóis buscaram a ajuda dos portugueses: queriam unir forças para o combate aos infiéis. Apesar de já estarem solicitando aos luso-brasileiros desde os primeiros anos do século XIX que não dessem abrigo aos infiéis, foi em 1805 que as propostas dos espanhóis sobre o assunto se radicalizaram. Neste ano, o comandante das tropas espanholas, Francisco Xavier de Viana, procurou diretamente o governador do Rio Grande, Paulo Gama, com a proposta de aniquilarem os infiéis. Viana solicitava permissão para entrar nas terras portuguesas em perseguição aos índios para, nas suas palavras: “[...] aniquilar-los á viva fuerza hasta dejar del todo concluida su raza detestable". Segundo Viana, tal atitude era necessária porque não ficava bem para duas nações "tão cultas", como era na sua visão Portugal e Espanha, terem em suas margens uma população "tão bárbara". ${ }^{17}$ A se dar crédito às fontes, o crescente enfrentamento entre espanhóis e infiéis estava gerando mútuos desejos de extinção e a disputa pela aliança com os portugueses era percebida por ambos como determinante naquela conjuntura.

A opinião dos portugueses sobre o assunto, porém, novamente não era homogênea. Três meses após a correspondência acima citada, Viana enviou outra carta, dessa vez ao comandante da 
fronteira de Rio Pardo, Patrício José da Câmara, na qual solicitava ajuda para um ataque aos índios. ${ }^{18} \mathrm{Na}$ visão de Correia da Câmara, tal aliança era possível e benéfica e, para tanto, escreveu para Paulo Gama pedindo-lhe que considerasse a proposta. Este, por sua vez, avaliava a situação de forma distinta. Agora, a desconfiança não era para com os índios como fora em outros momentos, mas quanto às reais intenções dos castelhanos. Segundo Gama, tratava-se de um subterfúgio para entrarem nos domínios do Rei Fidelíssimo com a intenção de recuperar o território dos sete povos das missões anexado pelos portugueses em 1801. ${ }^{19}$

Além disso, o governador não considerava uma boa estratégia geopolítica para o Império português o aniquilamento dos infiéis. Nas suas palavras, eles eram: “[...] pouco temíveis para haver-nos de jurar-lhe sua ruína total; como amigos nos podem vir a ser úteis em algumas conjunturas". ${ }^{20}$ Se fossem exterminados, a fronteira portuguesa da América meridional tornar-se-ia mais vulnerável. Ainda na sua visão, os infiéis não tinham a força necessária e, provavelmente, nem vontade de atacar os portugueses.

Os espanhóis, por sua vez, cedo perceberam que Gama não aprovaria o ataque aos índios, nem mesmo facilitaria as suas intenções de aniquilá-los. ${ }^{21}$ Assim, tudo parecia indicar que desta feita quem levaria a melhor na disputa da aliança com os portugueses seriam os infiéis. As coisas, porém, não se passaram bem assim. Segundo algumas informações, a despeito das proibições vigentes, certos funcionários luso-brasileiros da fronteira teriam entregado sorrateiramente uma quantidade de índios aos espanhóis. Apesar disso, um pequeno grupo de charruas chefiado por dom Gaspar, provavelmente ciente das divisões entre os lusos, procurou diretamente o governador em busca de apoio. $\mathrm{Na}$ ocasião, o cacique foi muito bem recebido na capital, Porto Alegre, selando por escrito um acordo que lhes oferecia uma série de garantias, inclusive contra eventuais ameaças dos próprios súditos portugueses. ${ }^{22}$

Para dom Gaspar e seu grupo, a árdua e descontínua construção de uma relação de amizade com os portugueses serviu como uma forma de garantia de determinados benefícios, mas não de maneira automática. $\mathrm{O}$ caso demonstra, como vários outros citados ao longo do texto, como mais do que uma mera aplicação mecânica 
de classificações pré-estabelecidas, de princípios formulados na corte ou de uma aliança regional imutável, os acordos, escritos ou verbais, eram pontuais e dependiam da articulação de diferentes interesses.

\section{Considerações finais}

Os diferentes momentos e situações mencionados anteriormente demonstram como as grandes categorias utilizadas para designar os diversos grupos presentes na região, índios infiéis, missioneiros, portugueses e espanhóis, eram fundamentalmente históricas. Sendo mutáveis, os seus próprios significados variavam de acordo com as diferentes conjunturas imperiais, com as dinâmicas locais e com os interesses individuais e coletivos dos sujeitos em interação.

Ao terem que lidar com constantes mudanças e indefinições, tanto os ibéricos quanto os índios se viam diante da difícil, e por vezes traiçoeira, tarefa de distinguir quem era quem: especialmente nos momentos de conflito, onde os aliados e os inimigos precisavam ser definidos em grandes categorias, não era fácil saber a quem elas correspondiam na prática. A questão é que as identidades, as amizades, as oportunidades e os interesses de todos os envolvidos não eram dados objetivos e tampouco homogêneos: atendiam a situações específicas e, frequentemente, a negociações muito particulares. Ao ser considerada como um produto histórico e dinâmico, a dicotomia entre castelhanos e missioneiros, por um lado, e portugueses e infiéis, especialmente minuanos, de outro, antes tida como estática e linear, adquire um novo lugar na compreensão do processo de formação da região fronteiriça. Mais do que uma representação automática de dois lados, funcionava como algum tipo de referência, ainda que um tanto difusa, com a qual os grupos e indivíduos lidavam ao elaborar as suas estratégias. Os resultados obtidos a partir da operacionalização de tais categorias, por sua vez, não eram garantidos nem definitivos: dependiam dos limites e das possibilidades inerentes às situações concretas. 


\section{IDENTITIES AND COLONIAL POLICIES: CHRISTIANIZED INDIANS, INFIDELS INDIANS, PORTUGUESE AND SPANIARDS IN THE RIVER PLATE REGION, C. 1750-1800}

Abstract: Until recently, the historiography on the River Plate region presented the relations of alliance prevailing in the region in a very schematic manner: the Christianized Guarani Indians would always be associated to the Spaniards and the Minuano to the Portuguese. Following the new perspectives over the native people history and focusing both the space of the Missions as the southern South America "Campanha" region, such relations have been gradually perceived in its complexity, which also included friendly approaches and even political alliances between the supposedly antagonistic groups. This article intends to approach the interactions between the many agents present at the time, considering the uses that they did of the different spaces and of the imperial commandments, emphasizing on how their initiatives and priorities not always were in line with the strict colonial classifications of the native people.

Keywords: Infidels Indians. Guarani. Borderlands. Missions. ${ }^{23}$

\section{Notas}

${ }^{1}$ Apesar das tentativas de alguns autores de esclarecer as diferenças entre eles, as fontes não são claras quanto a isso. Ao longo do processo de interação com a sociedade colonial portuguesa, os minuanos são os mais citados, mas as referências aos guenoas e charruas indicam uma proximidade ou até mesmo a possibilidade de se referirem a um mesmo grupo, talvez com diferenças ínfimas. Por considerar que tais classificações estavam em grande medida associadas às suas interações com a sociedade envolvente, como se verá ao longo do artigo, optei por utilizar os etnônimos específicos quando aparecem nas fontes e o termo infiel como uma forma de dar conta da presença indiscriminada das três nomenclaturas que, dependendo das circunstâncias, poderiam estar subsumidas naquele termo. Optei ainda por não utilizar aspas em infiel para não sobrecarregar o texto.

${ }^{2}$ FERGUSON e WHITEHEAD, 1992; BOCCARA, 2000; SCHWARTZ e SALOMON, 1999.

${ }^{3}$ Estado general de las doctrinas del Uruguay del año de 1707, en carta escrita al padre provincial de la Compañía de Jesus, por el padre Salvador de Rojas, fecha en el pueblo de Borja a 20 de diciembre de 1708. In: CORTESÃO e VIANNA, 1970 , p. 235-247.

${ }^{4}$ Situação das reduções do Uruguai em 1707. São Borja, 20-XII-1708. In: CORTESÃO e VIANNA, p. 1970, 239. 
${ }^{5} \mathrm{O}$ padre Nusdorfer, Superior das Missões do Uruguai, denuncia os intentos dos portugueses de povoar as cabeceiras e margens do Rio Negro, afluente do [rio] Uruguai. 29 de maio de 1749. In: CORTESÃO, 1951, p. 502-503.

${ }^{6}$ Carta y relación de las Misiones de la Provincia del Paraguay. Padre José Cardiel, S.J. Buenos Aires, 20 dic. 1747. Apud Bracco, 2004, 277.

7 Sobre o tema, veja-se: AXTELL, 1985; FARAGE; 1991; MEUWESE, 2003; WEBER, 2007.

${ }^{8}$ Arquivo Nacional, Rio de Janeiro (doravante citado como ANRJ) - cx.746, pct.02. Grifos meus.

${ }^{9}$ Ofício de Gomes Freire de Andrade para Sebastião José de Carvalho, em que se refere aos índios minuanos. Rio de Grande, 20 de fevereiro de 1755. In: Anais da Biblioteca Nacional, Rio de Janeiro, 1928, v. 50, p. 456.

${ }^{10}$ Carta de Gomes Freire de Andrade para dom José de Andonaegue. Arquivo Histórico Ultramarino (doravante citado como AHU) - Brasil - Limites, cx.2, doc. 101 .

${ }^{11}$ Carta do cacique minuano Bartolomeu a Rafael Pinto Bandeira, solicitando licença para passar aos domínios portugueses. Missões, 7 de maio de 1785. Biblioteca Nacional, Rio de Janeiro, 9, 4, 14 p. 511 n. 232 (em guarani), n. 233 (traduzida para o português).

${ }^{12}$ Carta de Rafael Pinto Bandeira para o Vice-Rei. Rio Grande, 16 de abril de 1786. ANRJ - cód.104, vol. 8, fl.101.

${ }^{13}$ Idem, fl.102-102v.

${ }^{14}$ Relação dos cinco caciques com quem falei e da gente que tem, e as causas porque querem vir para os Domínios de Portugal, e dos Animais com que se acham. José Carvalho da Silva, Tenente. AHU - Rio de Janeiro, cx.128, doc.10244.

${ }^{15}$ Há uma vasta bibliografia sobre o tema. Dentre os trabalhos mais importantes, veja-se: WEBER, 2007; HILL, 1996; ALMEIDA, 1997; DOMINGUES, 2000; GARCIA, 2009; ÁVILA, 1996; ORTELLI, 2007; QUARLERI, 2009.

${ }^{16}$ Ofício do [vice-rei do Estado do Brasil], Luís de Vasconcelos e Sousa, ao [secretário de estado da Marinha e Ultramar], Martinho de Melo e Castro, informando as propostas impraticáveis apresentadas pelo coronel Rafael Pinto Bandeira, como a passagem de famílias de índios Minuanos dos domínios espanhóis para o lado português, a fim de se fixarem nos terrenos de Vacaí com gados e outros animais; referindo as dificuldades a encontrar na execução de tal plano, e os conflitos que poderiam surgir nas relações luso-castelhanas. Rio de Janeiro, 30 de dezembro de 1786. AHU - Rio de Janeiro, cx. 128, doc. 10244.

${ }^{17}$ Ofício de Francisco Xavier Vianna Comandante das forças espanholas a Paulo José da Silva Gama, pedindo licença para entrar pelos domínios portugueses e aniquilar os índios infiéis, por ser vergonhoso que se conservassem no meio de duas nações cultas. Taquarembó-Chico, 25 de julho de 1805. Instituto Histórico 
e Geográfico Brasileiro (doravante citado como IHGB) - Arq. 1.2.19 - Conselho Ultramarino/Rio Grande do Sul, p. 263.

${ }^{18}$ Ofício de Francisco Xavier Vianna a Patrício José Correia da Câmara, para que reunisse os índios, que ele passaria ao Rio Grande para dar cabo deles. Taquarembó-Chico, 29 de outubro de 1805. IHGB - Arq.1.2.19. Conselho Ultramarino/Rio Grande do Sul.

${ }^{19}$ Ofício de Paulo José da Silva Gama a Patrício José Corrêa da Câmara, Comandante da Fronteira do Rio Pardo, mostrando-lhe como os índios como amigos, eram úteis e como inimigos, pouco temíveis para serem aniquilados. Porto Alegre, 13 de dezembro de 1805. IHGB - Arq. 1.2 .19 p. 268v

${ }^{20}$ Ofício de Paulo José da Silva Gama a Patrício José Corrêa da Câmara, Comandante da Fronteira do Rio Pardo, mostrando-lhe como os índios como amigos, eram úteis e como inimigos, pouco temíveis para serem aniquilados. Porto Alegre, 13 de dezembro de 1805. IHGB - Arq. 1.2.19 p. 268v

${ }^{21}$ Ofício de Jorge Pacheco para o vice-rei Marquês de Sobremonte. Campamento de Taquarembó chico, $1^{\circ}$. de febrero de 1806. In: ACOTSA Y LARA, 1998, p. 234-235.

${ }^{22}$ Ofício de Paulo José da Silva Gama ao Visconde de Anadia. Sobre as vantagens da paz que fizera com um chefe dos índios charruas - com o auto destas pazes. Porto Alegre, 25 de outubro de 1806. IHGB - Arq. 1.2.19, p. 286.

\section{Referências}

ACOSTA Y LARA, Eduardo F. La guerra de los charrúas. Montevidéu: Talleres de Loreto Editores, 1998.

ALMEIDA, Maria Regina Celestino de. Metamorfoses indigenas: identidade e cultura nas aldeias coloniais do Rio de Janeiro. Rio de Janeiro: Arquivo Nacional, 2003.

ALMEIDA, Rita Heloísa de. O Diretório dos índios: um projeto de civilização no Brasil do século XVIII. Brasília: Editora da Universidade de Brasília, 1997.

ÁVILA, Carlos Lázaro. El reformismo borbónico y los indígenas fronterizos americanos. In: GUIMERÁ, Agustín (Ed.). El reformismo borbónico. Madri: Alianza, 1996.

AXTELL, James. The invasion within: the contest of cultures in Colonial North America. New York: Oxford University Press, 1985.

AZARA, Félix. Viajes inéditos de don Félix de Azara desde Santa Fé del Paraguay, y a los pueblos de misiones. Buenos Aires: Imprenta y Librería de Mayo, 1873. 
- Memoria sobre el estado rural del Rio de la Plata y otros informes. Buenos Aires: Bajel, 1943 [c.1801 - c.1806].

BAUZA, Francisco. Historia de la dominación española en el Uruguay. Montevidéu: Talleres Graficos El Democrata, 1929

BOCCARA, Guillaume. Mundos Nuevos en las Fronteras del Nuevo Mundo: Relectura de los Procesos Coloniales de Etnogénesis, Etnificación y Mestizaje en Tiempos de Globalización, Mundo Nuevo Nuevos Mundos revista eletrônica, Paris, 2000. Disponível em: <www.ehess.fr/cerma/Revue/debates.htm>. Acesso em: 15 de jul. 2010.

BOLTON, Herbert Eugene. La misión como institución de la frontera en el septentrión de Nueva España [1917], Estudios (Nuevos y Viejos) sobre la frontera, Anexo 4 Revista de Indias 1990, Madri, CSIC, p. 45-60.

BOXER, Charles. A Igreja e a Expansão Ibérica (1440-1770). Lisboa: Edições 70, 1989.

BRACCO, Diego. Charrúas, guenoas y guaranies. Interacción y destrucción: indígenas en el Río de la Plata. Montevidéu: Linardi y Risso, 2004.

BROWN, Jennifer; VIBERT, Elizabeth. Introduction. In: (Eds.). Reading beyond words: contexts for native history. Toronto: Broadview Press, 2003.

CORTESÃO, Jaime; VIANNA, Helio (introdução, notas e sumário). Jesuitas e bandeirantes no Uruguai (1611-1758). Rio de Janeiro: Biblioteca Nacional, 1970. (organização e anotação). Alexandre de Gusmão e o Tratado de Madri. parte III: Antecedentes do Tratado, tomo II. Rio de Janeiro: Ministério das Relações Exteriores, Instituto Rio Branco, 1951.

DOMINGUES, Ângela. Quando os indios eram vassalos: colonização e relações de poder no Norte do Brasil na segunda metade do século XVIII. Lisboa: Comissão Nacional para as Comemorações dos Descobrimentos Portugueses, 2000.

FARAGE, Nádia. As muralhas dos sertões: os povos indígenas no Rio Branco e a colonização. Rio de Janeiro: Paz e Terra; ANPOCS, 1991.

FERGUSON, R. Brian; WHITEHEAD, Neil. The Violent Edge of Empire. In: (Eds.). War in tribal zone: expanding states and indigenous warfare. New Mexico: School of American Research Press, 1992.

GARCIA, Elisa Frühauf. As diversas formas de ser indio: políticas indígenas e políticas indigenistas no extremo sul da América portuguesa. Rio de Janeiro: Arquivo Nacional, 2009. 


\section{Elisa Frühauf Garcia}

HENIS, Pe. Tadeo Xavier. Diario histórico de la rebelión y guerra de los pueblos guaranís, situados en la costa oriental del río Uruguay, del año de 1754. Alicante: Biblioteca Virtual Miguel de Cervantes, 2002.

HILL, Jonathan. Introduction. In: (Org.). History, power and identity: ethnogenesis in the Americas, 1492-1992. Iowa City: University of Iowa Press, 1996.

. Contested Pasts and the Practice of Anthropology: Overview. American Anthropologist, v. 94, n. 4, p. 811, 1992.

LANDERS, Jane. Gracia Real de Santa Teresa de Mose: A Free Black Town in Spanish Colonial Florida. The American Historical Review. February, v. 95, n. 1. p. 21, 1990.

LANGFUR, Hal. Uncertain Refuge: Frontier Formation and the Origins of the Botocudo War in Late Colonial Brazil: Hispanic American Historical Review, v. 82, n. 2, 2002 .

MEUWESE, Marcus P. For the Peace and Well-Being of the Country: Intercultural Mediators and Dutch-Indian Relations in New Netherland and Dutch Brazil, 1600-1664. Tese de PhD em História, Universidade de Notre Dame, EUA, 2003.

MONTEIRO, John. Tupis, tapuias e historiadores. Estudos de história indígena e do indigenismo. Tese apresentada no concurso de livre docência na Universidade Estadual de Campinas. Campinas, 2001.

MORNER, Magnus. La mezcla de razas en la historia de América Latina. Buenos Aires: Paidós, 1969.

ORTELLI, Sara. Trama de una guerra conveniente: Nueva Vizcayay la sombra de los apaches (1748-1790). México: El Colegio de México, Centro de Estudios Históricos, 2007.

QUARLERI, Lia. Rebelión y guerra en las fronteras del Plata. Guaranies, jesuitas e impérios coloniales. Buenos Aires: FCE, 2009.

RAPPAPORT, Joanne. Introduction: Interpreting the Past. In: . The Politics of Memory. Cambridge: Cambridge University Press, 1990.

SANTOS, Maria Cristina dos; BAPTISTA, Jean Tiago. Reduções jesuíticas e povoados de índios: controvérsias sobre a população indígena (séc. XVII-XVIII), História Unisinos, v. 11, n. 2, p. 240-251, maio/ago. 2007.

SCHWARTZ, Stuart; SALOMON, Frank. New Peoples and New Kinds of People: Adaptation, Readjustment, and Ethnogenesis in South American Indigenous Societies. In: The Cambridge History of the Native Peoples of the Americas. Vol. III: South America, part 2. Cambridge New York: Cambridge University Press, 1999. 
SIDER, Gerald. Identity as History. Ethnohistory, Ethnogenesis and Ethnocide in the Southeastern United States. Identities Global Studies in Culture and Power. New Hampshire, v. 1, 1994.

SWEET, David. The Ibero-American Frontier Mission in Native American History. In: LANGER, Erick; JACKSON, Robert. The New Latin American Mission History. Lincoln: University of Nebraska Press, 1995.

6 WEBER, David. Borbones y bárbaros: centro y periferia en la reformulación de la política de España hacia los indígenas no sometidos. Anuário IEHS, Tandil, n. 13, p. 147-171, 1998.

. Bárbaros. Los españoles y sus salvajes en la era de la ilustración. Barcelona: Crítica, 2007.

WILDE, Guillermo. Religión y poder en las misiones de guaranies. Buenos Aires: SB, 2009.

Recebido em: 05/03/2012.

Aprovado em: 20/04/2012. 